\title{
Nitrogen and phosphorus additions negatively affect tree species diversity in tropical forest regrowth trajectories
}

\author{
Ilyas Siddique, ${ }^{1,5}$ Ima Célia Guimarães Vieira, ${ }^{2}$ Susanne Schmidt, ${ }^{1}$ David Lamb, ${ }^{1}$ Cláudio José Reis Carvalho, ${ }^{3}$ \\ Ricardo de Oliveira Figueiredo, ${ }^{3}$ Simon Blomberg, ${ }^{1}$ and Eric A. Davidson ${ }^{4}$ \\ ${ }^{1}$ University of Queensland, School of Biological Sciences, Brisbane, Queensland 4072 Australia \\ ${ }^{2}$ Museu Paraense Emílio Goeldi, Coordenação de Botânica, CP 399, CEP 66040-170, Belém, Pará, Brazil \\ ${ }^{3}$ Empresa Brasileira de Pesquisa Agropecuária, EMBRAPA Amazônia Oriental, CEP 66095-100, Belém, Pará, Brazil \\ ${ }^{4}$ Woods Hole Research Center, 149 Woods Hole Road, Falmouth, Massachusetts 02540-1644 USA
}

\begin{abstract}
Nutrient enrichment is increasingly affecting many tropical ecosystems, but there is no information on how this affects tree biodiversity. To examine dynamics in vegetation structure and tree species biomass and diversity, we annually remeasured tree species before and for six years after repeated additions of nitrogen $(\mathrm{N})$ and phosphorus $(\mathrm{P})$ in permanent plots of abandoned pasture in Amazonia. Nitrogen and, to a lesser extent, phosphorus addition shifted growth among woody species. Nitrogen stimulated growth of two common pioneer tree species and one common tree species adaptable to both high- and lowlight environments, while P stimulated growth only of the dominant pioneer tree Rollinia exsucca (Annonaceae). Overall, $\mathrm{N}$ or $\mathrm{P}$ addition reduced tree assemblage evenness and delayed tree species accrual over time, likely due to competitive monopolization of other resources by the few tree species responding to nutrient enrichment with enhanced establishment and/or growth rates. Absolute tree growth rates were elevated for two years after nutrient addition. However, nutrient-induced shifts in relative tree species growth and reduced assemblage evenness persisted for more than three years after nutrient addition, favoring two nutrientresponsive pioneers and one early-secondary tree species. Surprisingly, $\mathrm{N}+\mathrm{P}$ effects on tree biomass and species diversity were consistently weaker than $\mathrm{N}$-only and P-only effects, because grass biomass increased dramatically in response to $\mathrm{N}+\mathrm{P}$ addition. The resulting intensified competition probably prevented an expected positive $\mathrm{N}+\mathrm{P}$ synergy in the tree assemblage. Thus, $\mathrm{N}$ or $\mathrm{P}$ enrichment may favor unknown tree functional response types, reduce the diversity of coexisting species, and delay species accrual during structurally and functionally complex tropical rainforest secondary succession.
\end{abstract}

Key words: biodiversity loss; clay Oxisol; ecosystem fertilization; mixed-effects models; $N$ and $P$ colimitation; $N+P$ synergism; niche dimensionality; spatial heterogeneity; tree-grass interactions; tree species richness; tropical moist forest recovery; vegetation development.

\section{INTRODUCTION}

Human food production and energy use have increased nitrogen and phosphorus fluxes in ecosystems by up to 10 -fold in some regions, while other regions are experiencing nutrient impoverishment (Falkowski et al. 2000, Howarth et al. 2005). Both nutrient-enriched and impoverished regions occur in the tropics near or at hotspots of global biodiversity (Howarth et al. 2005). Enrichment with the nutrients limiting primary productivity plays an important role in biodiversity loss in temperate ecosystems (Wassen et al. 2005, Clark et al. 2007). In biodiversity-rich, functionally complex, and

Manuscript received 14 April 2009; revised 17 September 2009; accepted 30 September 2009; final version received 26 October 2009. Corresponding Editor: J. J. Battles.

${ }^{5}$ Present address: Centro de Investigaciones en Ecosistemas, Universidad Nacional Autónoma de México, UNAM Campus Morelia, Antigua carretera a Pátzcuaro 8701, Col. Exhacienda San José La Huerta, C.P. 58190, Morelia, Michoacán, Mexico. E-mail: ilysid@gmail.com highly dynamic ecosystems such as tropical secondary forests the relationship between biodiversity and nutrient limitation remains unknown.

Low soil $\mathrm{P}$ availability limits primary productivity on the widespread, deeply weathered lowland tropical Oxisols (Vitousek and Sanford 1986, Elser et al. 2007). However, after land use change the resulting ecosystems may become limited by nitrogen (Davidson et al. 2007). Deforestation, subsequent land use, and repeated burning can cause large losses through volatilization of $\mathrm{N}$ and through ash transport, leaching, and erosion of both $\mathrm{N}$ and $\mathrm{P}$ (Kauffman et al. 1995, Williams and Melack 1997). Nutrient impoverishment may thus slow post-abandonment biomass accumulation during secondary succession (Gehring et al. 1999, Davidson et al. 2004) and, thereby, accrual of mature forest species, which are most at risk among tropical forest species biodiversity (Martínez-Garza and Howe 2003, Chazdon 2008).

By contrast, enrichment with limiting nutrients accelerates biomass accumulation and might thereby 
accelerate secondary succession and forest recovery. However, enrichment with limiting nutrients in relatively simple ecosystems has widely been reported to cause species loss in herbaceous, shrub, epiphyte, and fungal assemblages, impairing biodiversity conservation and perhaps ecosystem function, although evidence is almost entirely restricted to temperate ecosystems (Bobbink et al. 1998, 2010, Fynn and O'Connor 2005, Wassen et al. 2005, Clark et al. 2007). Conversely, P fertilization in tropical montane forest dramatically increased abundance and diversity of epiphytes across functional groups without concominant species loss (Benner and Vitousek 2007). In N-fertilized tropical montane forest, Ostertag and Verville (2002) found lower understory plant species richness than in controls, but pre-fertilization data were unavailable. We did not find reports of nutrient enrichment affecting trajectories of tree assemblage composition or diversity over time in any biome.

Mechanisms for $\mathrm{N}$-induced species loss may include reduced heterogeneity of soil nutrient availability (Gilliam 2006) and soil acidification (Bobbink et al. 1998, Fynn and O'Connor 2005, Clark et al. 2007). Competition for other nutrients or light may also be intensified, potentially favoring species efficient at their acquisition and use (Herbert et al. 2004), thereby increasing local extinction of and/or reducing colonization by other species (Wilson and Tilman 2002), for instance those adapted to low nutrient availability (Bobbink et al. 1998). Similarly, P enrichment may cause competitive exclusion of species, although species responses to $\mathrm{N}$ and $\mathrm{P}$ addition may vary due to fundamental differences in plant strategies for $\mathrm{N}$ and $\mathrm{P}$ acquisition (Lambers et al. 2008).

Theory predicts that simultaneous enrichment with co-limiting nutrients reduces the number of simultaneously limiting resources, thereby reducing niche dimensions among which species may coexist (Harpole and Tilman 2007). Thus, it may be hypothesized that simultaneous enrichment with $\mathrm{N}$ and $\mathrm{P}$ in tropical secondary forests causes greater biomass response and greater loss in tree species diversity than single-nutrient enrichment (Tanner et al. 1998, Lawrence 2003).

In tropical secondary forests, species favored by nutrient enrichment may be fast-growing pioneers with high photosynthetic rates (Ellsworth and Reich 1996, Lawrence 2003). The resulting potential delays in species replacement during succession may hinder the recovery of large-seeded mature forest species by prolonging the persistence of early-successional tree species (Mesquita et al. 2001, Martínez-Garza and Howe 2003) in tropical landscapes increasingly dominated by secondary vegetation (Chazdon 2008).

The short-term nature of previous nutrient addition experiments in tropical secondary forests (Harcombe 1977, Gehring et al. 1999, Davidson et al. 2004) precludes interpretation of nutrient effects on the dynamics of composition or diversity. The high taxonomic, structural, and largely unknown functional diversity of tropical secondary forests (Chazdon 2008) may limit the applicability of mechanistic explanations demonstrated for nutrient enrichment affecting temperate plant communities. Furthermore, highly differentiated strategies of nutrient acquisition and use (Lambers et al. 2008) complicate the relationship between ecosystem nutrient limitation and nutrient-induced shifts in community composition and diversity (Tanner et al. 1998). We hypothesized that nutrient enrichment negatively affects tree species diversity by disproportionately promoting few, nutrient-responsive pioneer species.

To assess how $\mathrm{N}$ and $\mathrm{P}$ enrichment affects tree community dynamics, we related trajectories of vegetation structure, tree species diversity, and evenness with absolute shifts in species woody biomass estimates for six years, in response to factorial $\mathrm{N}$ and $\mathrm{P}$ addition in lowland Amazonia. We chose a well-studied pasture site, abandoned after prolonged use and frequent fires on naturally infertile, deeply weathered clay Oxisol.

\section{Methods}

\section{Site description}

The study was conducted at Fazenda Vitória, Paragominas, Pará, Brazilian Amazonia $\left(2^{\circ} 59^{\prime} \mathrm{S}, 47^{\circ} 31^{\prime} \mathrm{W}\right)$, where many studies have been completed on the ecology of abandoned pastures and forests (e.g., Uhl et al. 1988, Nepstad et al. 1994, 1996, Vieira et al. 1994, Verchot et al. 1999, Davidson et al. 2004, 2007, Markewitz et al. 2004). Annual rainfall of $1800 \mathrm{~mm}$ is highly seasonal, i.e., $<100 \mathrm{~mm}$ monthly for six months and $35 \mathrm{~mm}$ monthly during the driest consecutive three months of July-September (Jipp et al. 1998). Mature and secondary forests in the region remain evergreen, despite the pronounced dry season, by extracting water from deep subsoil layers (Nepstad et al. 1994), although some early-successional species shed a substantial portion of their foliage during the dry season (Davidson et al. 2004).

The Kaolinitic Yellow Latosol soils (USDA: Haplustox) in the region have developed on Belterra clay and Tertiary Barreiras formations (Sombroek 1966). These deeply weathered sediments consist mainly of kaolinite, quartz, and hematite, with $60-80 \%$ clay and $<9 \%$ sand content at the study site. Pasture soil $\mathrm{pH}$ in water decreases with depth from 5.7 at the surface. Most actively managed pastures in this region have been fertilized with P starting in the late 1980s and early 1990s (Dias-Filho et al. 2001). However, the degraded cattle pasture used in this study was never fertilized prior to the experiment and was abandoned before fertilization became common. Soil solution $\mathrm{N}$ fluxes and soil available $\mathrm{P}$ in abandoned pastures and in a 19-year-old secondary forest in the region were very low compared to mature forest. (For detailed nutrient budgets of these land use systems within a few kilometers of our plots, see Markewitz et al. [2004].) 
The study was undertaken in 7.25 ha of abandoned pasture that was originally planted in 1971 with the grass Panicum maximum and abandoned in 1984. The pasture was grazed by cattle in a rotation regime, with 1 animal/ha, and was periodically burned and then sprayed with herbicide. Accidental fires have burned the area at least three times since abandonment, the last time being 1993. We started the experiment six years after the last fire, when forbs, shrubs, and trees dominated and grass cover had diminished.

\section{Nutrient addition: experimental design}

Six years after the last fire (i.e., 15 years after pasture was abandoned), four plots $(20 \times 20 \mathrm{~m})$ were established in each of three replicate blocks in a randomized complete block design. The four plots within each block received the following treatments at the beginning of two consecutive rainy seasons (January 2000 and February 2001): "C" (control), "N" (100 kg N/ha as urea), "P" (50 kg P/ha as simple superphosphate), and "N + P" at these same rates. Fertilizers were broadcast by hand in each of four $10 \times 10 \mathrm{~m}$ subplots per fertilized $20 \times 20 \mathrm{~m}$ plot to homogenize distribution. The full factorial design is composed of two crossed binary factors of nutrient addition ("-N" vs. " $+\mathrm{N}$ " and " $-\mathrm{P}$ " vs. " $+\mathrm{P}$ "), with $n=6$ plots, i.e., a combined area of 0.24 ha in each level for the main effects. At the end of the dry season before the first nutrient addition, the baseline census was carried out. Taxonomic identity at the species level, height, and diameter at breast height (dbh, at $1.3 \mathrm{~m}$ above ground level) of all trees $\geq 2 \mathrm{~cm} \mathrm{dbh}$ were measured and permanently marked with individual ID numbers at breast height. Height and dbh of all individual trees, including recruits into the $\geq 2 \mathrm{~cm}$ dbh size class, were remeasured annually at the end of the subsequent six wet seasons, so as to minimize the impact of diameter variability caused by differential stem hydration among trees. For a detailed description of the present experiment with early results see Davidson et al. (2004).

\section{Univariate data analyses}

Woody biomass was estimated from a generic allometric equation developed by Uhl et al. (1988) in comparable abandoned pastures at this same ranch:

$$
\begin{aligned}
\ln (\text { woody biomass })= & -2.17+1.02 \ln \left(\text { diameter }^{2}\right) \\
& +0.39 \ln (\text { height })
\end{aligned}
$$

where biomass is in megagrams per hectare, diameter is in centimeters, and height is in meters. Due to interspecific differences in the relationship between diameter, height, and true biomass, species biomass estimates presented here are general approximations, but are more precise estimations than basal area alone, because they are based on height as well as dbh of each individual tree remeasured at each census.
In order to account for the initial spatial variation at the plot and block scales before treatment application, we tested for the effects of nutrient addition on the rates of change (i.e., slopes) of univariate response variables over time. To achieve this, we fitted ordinary linear mixed-effects regression models, because they specifically account for temporal autocorrelation among remeasurements and are capable of modeling spatial variation as random effects of blocks, and plots nested within blocks, using the "nlme" package, version 3.1-83 in R 2.6.0 (Pinheiro et al. 2007). We compared the simplest linear model with ecologically meaningful alternatives by including quadratic terms for time and covariates (i.e., density of individuals or initial condition of response variable prior to nutrient addition). Subsequently, we selected the simplest model of best fit that (1) satisfied assumptions of independence, normality, and homogeneity of variances and that (2) had the lowest Akaike's information criterion (AIC). The detailed statistical procedure is reported in Appendix A.

We report effects of nutrient addition where we observed a significant effect on slopes of the response variable, i.e., where interactions were significant between factors of nutrient addition ( $\mathrm{N}$ or $\mathrm{P}$ ) and time, or squared time $\left(\right.$ time $\left.^{2}\right)$ in second-order polynomial models (e.g., $\mathrm{N} \times$ time, $\mathrm{P} \times$ time, $\mathrm{N} \times \mathrm{P} \times$ time, $\mathrm{N} \times$ time $^{2}$, etc.). This interpretation of interactions with time (e.g., $\mathrm{N} \times$ time) is valid, because the central assumption was satisfied that none of the main effects of factors of nutrient addition (i.e., $\mathrm{N}, \mathrm{P}, \mathrm{N} \times \mathrm{P}$ ) were significant. For reported significant model terms, we give $t$ values of Wald tests (in parentheses), subscripted by the corresponding degrees of freedom $\left(t_{\mathrm{df}}\right)$, followed by the significance level (fitted equations may be found in Appendices A, B, and C). All graphs were produced using the "graphics" package in R 2.6.0 (R Development Core Team 2007). All diversity calculations were performed using the "vegan" package, version 1.8-8 in R 2.6.0 (Oksanen et al. 2007).

\section{RESUltS}

Initial variation among blocks (and plots) exceeded (fixed) effects of nutrient addition. Therefore, initial variation among blocks and plots is modeled here as random effects, based on repeated measures of all plots. This approach enabled testing for nutrient effects on slopes (rather than means) of response variables as they varied with time, thereby allowing visualization of changes in tree density and woody biomass, grass biomass, tree species richness, and evenness, as well as absolute shifts in growth rates among tree species.

\section{Tree density and biomass and grass biomass}

Between 6 and 12 years after the last stand-clearing fire (i.e., 15-21 years since pasture abandonment), total densities of individual trees generally increased over time, but varied widely among plots (Fig. 1a). Net 

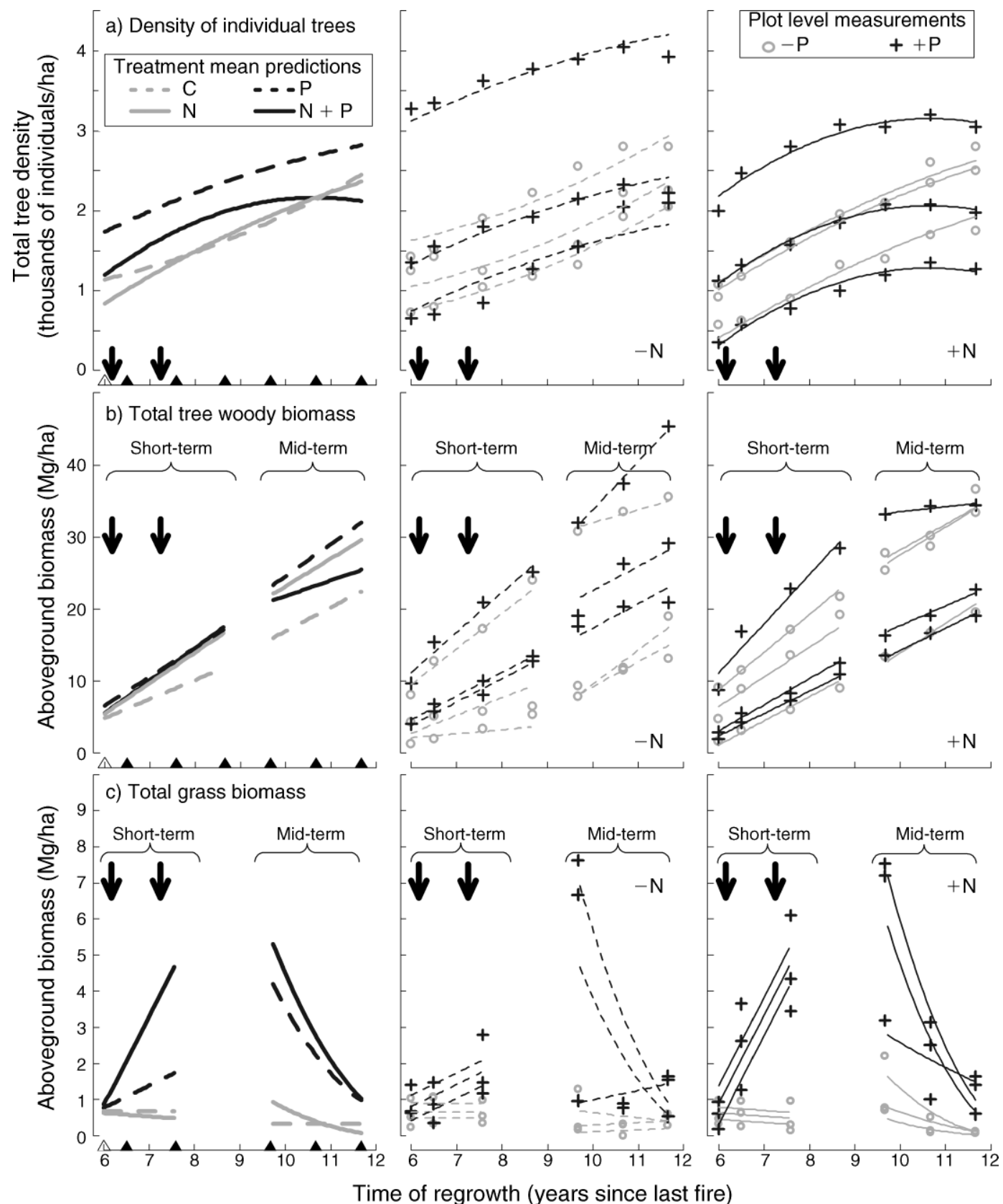

FIG. 1. Trajectories of vegetation structure in secondary regrowth in response to factorial $\mathrm{N}$ and $\mathrm{P}$ addition in abandoned pasture, Brazilian Amazonia, following regrowth after fire. Left-hand panels show predictions (i.e., best linear unbiased predictors, BLUP) for treatment means (fixed effects of mixed models). Triangles on the $x$-axis indicate timing of censuses. Middle panels (controls and $\mathrm{P}$ only) and right-hand panels $(\mathrm{N}$ only and $\mathrm{N}+\mathrm{P}$ ) show all plot-level measurements and plot-level predictions. Arrows indicate timing of nutrient additions. For all fitted equations, see Appendix A. (a) Sum of all tree species' density of individuals with second-order polynomial fits (no covariate). (b) Sum of all tree species' aboveground woody biomass with linear fits (covariate: initial biomass) for short-term responses within two wet seasons of the last nutrient addition and subsequent midterm biomass trajectory after three wet seasons following the last nutrient addition. (c) Sum of all grass species aboveground biomass with linear fits for short-term responses (no covariate; missing census: year 8.7) and subsequent midterm biomass trajectory (covariates: year 9.7 biomass, power of variance).

recruitment of individuals leveled off at approximately year 11 in half of all plots, but this occurred at densities ranging from 1300 to 3100 trees/ha. Model selection resulted in the second-order polynomial fit without covariates. Consistently greater slopes in plots amended with $\mathrm{N}\left(\mathrm{N} \times\right.$ time, $\left.t_{64}=2.65, P<0.01\right)$ revealed higher rates of accrual of individuals in response to $\mathrm{N}$ addition (Fig. 1a), but this effect diminished over time $(\mathrm{N} \times$ 
time $\left.^{2}, t_{64}=-2.24, P<0.05\right)$, while accrual of individuals also diminished in plots amended with $\mathrm{P}\left(\mathrm{P} \times \operatorname{time}^{2}, t_{64}=\right.$ $-2.18, P<0.05)$.

Between 6 and 12 years after the last fire, total tree aboveground woody biomass estimates showed, on average, a fivefold increase (Fig. 1b). To permit comparison with other studies on fertilization effects, we present the simplest linear model of total woody biomass with initial biomass as covariate. To this end we distinguish separate models for: (1) short-term linear responses within two wet seasons of last nutrient addition, on which other published studies report (Gehring et al. 1999), and (2) subsequent midterm trajectories from three wet seasons after last nutrient addition, for which we are unaware of any published comparison. The short-term fit indicated positive effects of $\mathrm{N}$ addition $\left(\mathrm{N} \times\right.$ time, $\left.t_{28}=3.14, P<0.01\right)$, i.e., after accounting for the effects of initial biomass on subsequent trajectories, $\mathrm{N}$ addition resulted on average in faster total woody biomass growth within two wet seasons of last nutrient addition (Fig. 1b, short-term). However, an equivalent linear fit of the subsequent midterm trajectories revealed no difference due to $\mathrm{N}$ addition $(P>0.1$; Fig. $1 \mathrm{~b}$, midterm). By contrast, $\mathrm{P}$ addition did not significantly increase the rates of shortterm biomass accumulation $(\mathrm{P} \times$ time, $P>0.1)$, possibly partly due to high variation among $+\mathrm{P}$ plots.

Total aboveground grass biomass was also modeled as separate short-term and midterm linear fits (Fig. 1c; cases with missing values omitted). Within 1.5 years of first nutrient addition, grass biomass increased fivefold in $\mathrm{N}+\mathrm{P}$ plots $\left(\mathrm{N} \times \mathrm{P} \times\right.$ time, $\left.t_{20}=3.57, P<0.01\right)$. Within the same period, grass biomass tended to double after P-only addition $(\mathrm{P} \times$ time, $P>0.1)$ and was unaffected by $\mathrm{N}$-only addition.

Three wet seasons after last nutrient addition, grass biomass in $+\mathrm{P}$ plots was several-fold higher than at baseline census, though highly variable (Fig. 1c), and subsequently collapsed to baseline levels. Model selection for the midterm period included covariates of grass biomass at year 9.7 (grass9.7), and a variance power covariate, which accounted for heteroscedasticity observed in the midterm (Fig. 1c). The rate of midterm grass biomass decline was primarily predicted by its initial value (grass $9.7_{9} \times$ time $t_{18}=-4.41, P<0.001$ ), without significant effects of nutrient addition. This sudden collapse of grass biomass coincided with a significant decline over time in the negative $\mathrm{N} \times \mathrm{P}$ interactions of woody biomass of both Zanthoxylum rhoifolium Lam. (Rutaceae) and Banara guianensis Aubl. (Flacourtiaceae) and of rarefied species richness $\left(\mathrm{N} \times \mathrm{P} \times \mathrm{time}^{2}, t_{52}=2.62, P<0.05 ; t_{52}=2.57, P<\right.$ 0.05 ; and $t_{63}=-2.09, P<0.05$; in Figs. $3 \mathrm{~b}, 3 \mathrm{c}$, and $2 \mathrm{a}$, respectively).

Tree species richness and evenness

The observed tree species richness increased from 36 to 54 in the total pooled 0.48 ha of experimental plots between 6 and 12 years after the last fire. We accounted for the observed high variation in numbers of individual trees per plot (cf. Fig. 1a) by individual-based rarefaction curves (not shown; rationale in Appendix B). The resulting rarified species richness represents the number of species in a random subsample of 13 individuals $\left(R_{13}\right)$. Model selection for $R_{13}$ led to a second-order polynomial fit with initial $R_{13}$ as covariate (Fig. 2a). Both $\mathrm{N}$ and $\mathrm{P}$ addition had a negative effect of similar size on increases in $R_{13}$ over time ( $\mathrm{N} \times$ time, $t_{63}=-2.89$, $P<0.01 ; \mathrm{P} \times$ time, $\left.t_{63}=-3.14, P<0.01\right)$. However, effect sizes diminished significantly over time $\left(\mathrm{N} \times\right.$ time $^{2}$, $t_{63}=2.34, P<0.05 ; \mathrm{P} \times$ time $\left.^{2}, t_{63}=3.12, P<0.01\right)$. In $\mathrm{N}+\mathrm{P}$ plots the negative effect of nutrient addition was weaker than the sum of main effects $\left(\mathrm{N} \times \mathrm{P} \times\right.$ time, $_{63}=$ 2.11, $P<0.05)$.

Model selection for the other component of tree species diversity, measured as the Simpson evenness measure $\left(E_{1 / D}\right)$, resulted in a second-order polynomial fit with density of individuals as covariate (Fig. 2b). Nitrogen addition had a greater, negative effect on $E_{1 / D}$ trajectories $\left(\mathrm{N} \times\right.$ time, $\left.t_{55}=-3.27, P<0.01\right)$ than $\mathrm{P}$ addition $\left(\mathrm{P} \times\right.$ time, $\left.t_{55}=-2.31, P<0.05\right)$. Similar to $R_{13}$, less-than-additive $\mathrm{N} \times \mathrm{P}$ interactions were significant $\left(\mathrm{N} \times \mathrm{P} \times\right.$ time, $\left.t_{55}=2.33, P<0.05\right)$. However, there was no evidence of a diminishing effect size over time (both $\mathrm{N} \times$ time $^{2}$ and $\mathrm{P} \times$ time $^{2}, P>0.1$ ).

The Simpson diversity index $(1-D)$ showed a delaying effect of $\mathrm{P}$ addition on tree species diversity increases over time (second-order polynomial fit; covariate initial $1-D ; \mathrm{P} \times$ time, $t_{56}=-2.89, P<0.01 ; \mathrm{P} \times$ time $^{2}, t_{56}=2.59, P<0.05$; Fig. $2 \mathrm{c}$ ). This matched the response of $R_{13}$ to $\mathrm{P}$ addition, but was nonsignificant for $\mathrm{N}$ addition.

\section{Species woody biomass}

Fitting mixed models to individual species' aboveground woody biomass estimates revealed important interspecific differences in nutrient responses. The dominant tree species, Rollinia exsucca A.DC. (Annonaceae), accounted for $64 \%$ of initial total woody biomass and was the only species to respond to both $\mathrm{N}$ and $\mathrm{P}$ additions $\left(\mathrm{N} \times\right.$ time, $t_{52}=3.77, P<0.001 ; \mathrm{P} \times$ time, $t_{52}=3.93, P<0.001$; Fig. $\left.3 \mathrm{a}\right)$, but with less-thanadditive effects of $\mathrm{N}+\mathrm{P}\left(\mathrm{N} \times \mathrm{P} \times\right.$ time, $t_{52}=-2.42, P<$ 0.05). Negative interactions of both $\mathrm{N}$ and $\mathrm{P}$ with the quadratic term of time $\left(\mathrm{N} \times\right.$ time $^{2}, t_{52}=-2.46, P<0.05$; $\mathrm{P} \times$ time $\left.^{2}, t_{52}=-2.14, P<0.05\right)$ indicated diminishing effect sizes for both nutrients on woody biomass of $R$. exsucca. Overall, $R$. exsucca reached a biomass plateau by 12 years after the last fire.

Codominant Zanthoxylum rhoifolium and initially rare Banara guianensis contributed $12 \%$ and $0.8 \%$ of total initial woody biomass, respectively. Both species responded positively to $\mathrm{N}$ addition ( $Z$. rhoifolium, $\mathrm{N} \times$ time, $t_{52}=3.04, P<0.01 ; B$. guianensis, $\mathrm{N} \times$ time, $t_{52}=$ 3.82, $P<0.001$; in Figs. $3 \mathrm{~b}$ and $3 \mathrm{c}$, respectively), but 

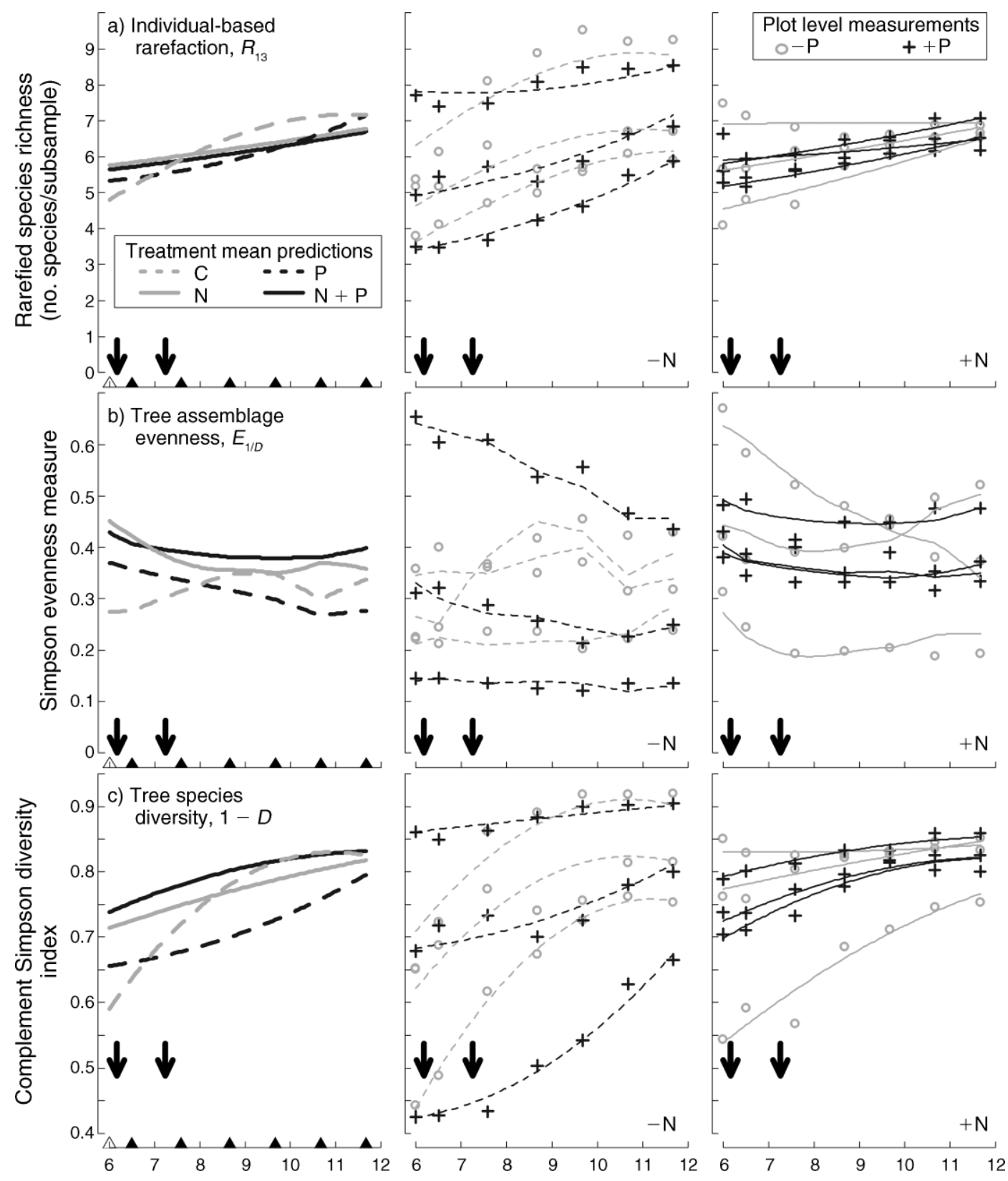

Time of regrowth (years since last fire)

FIG. 2. Trajectories of tree species diversity in secondary regrowth in response to factorial $\mathrm{N}$ and $\mathrm{P}$ addition in abandoned pasture, Brazilian Amazonia. Left-hand panels show predictions (i.e., best linear unbiased predictors, BLUP) for treatment means (fixed effects of mixed models). Triangles on the $x$-axis indicate timing of censuses. Middle panels (controls and $\mathrm{P}$ only) and righthand panels $(\mathrm{N}$ only and $\mathrm{N}+\mathrm{P}$ ) show all plot-level measurements and plot-level predictions. Arrows indicate timing of nutrient additions. For all equations, see Appendix B. (a) Tree species richness in a random subsample of 13 individual trees $\left(R_{13}\right)$ for each plot $\times$ census combination: second-order polynomial fit (covariate: initial $\left.R_{13}\right)$. (b) Simpson evenness measure $\left(E_{1 / D}\right)$ : second-order polynomial fit (covariate: density of individual trees, linearly interpolated between successive censuses). (c) Complement of Simpson diversity index $(1-D)$ : second-order polynomial fit (covariate: initial $1-D)$.

also showed diminishing $\mathrm{N}$ responses over time $(Z$. rhoifolium, $\mathrm{N} \times$ time $^{2}, t_{52}=-3.28, P<0.05 ; B$. guianensis, $\mathrm{N} \times$ time $\left.^{2}, t_{52}=-3.76, P<0.001\right)$. Furthermore, both species also exhibited a less-thanadditive effect of $\mathrm{N} \times \mathrm{P}\left(Z\right.$. rhoifolium, $\mathrm{N} \times \mathrm{P} \times$ time, $_{52}$
$=-2.48, P<0.05 ;$ B. guianensis, $\mathrm{N} \times \mathrm{P} \times$ time, $t_{52}=$ $-3.82, P<0.001)$.

All other 55 observed tree species either showed no significant nutrient response or had abundances too low across treatments and censuses to permit univariate fits 
without violating model assumptions. The most abundant nonresponsive species was Vismia guianensis (Aubl.) Choisy (Clusiaceae). Pooled biomass increments of these 55 species generally increased over time, regardless of nutrient addition $(\mathrm{N} \times$ time, $\mathrm{P} \times$ time, and $\mathrm{N} \times \mathrm{P} \times$ time, $P>0.1$; Fig. $3 \mathrm{~d})$.

\section{Discussion}

We observed high inter-block and inter-plot variation, presumably attributable to spatial variation in soil conditions and in seed dispersal, as well as to plot size. Based on the pre-fertilization baseline census, our mixed-model analysis was able to account for this spatial heterogeneity among blocks and plots, which was independent of treatment application. This enabled us to detect the effects of nutrient addition on the rate of change (i.e., slope) and the duration of these effects (based on changes in slope over time) of tree species biomass and diversity. Regular remeasurement of floristic attributes, over several years beyond the previously reported short-term nutrient enrichment responses, revealed short-lived effects of the original nutrient additions on woody biomass accumulation. However, nutrient enrichment effects on assemblage evenness persisted for more than three years.

The scope to generalize from these findings is limited, because this study intentionally focused on a single region to control extraneous variables known to affect successional trajectories, such as climate, soil type, land use history, and the landscape matrix (Chazdon 2003). This enabled sensitive direct detection of treatment response trajectories and consistent negative $\mathrm{N} \times \mathrm{P}$ synergies associated with tree-grass competition. Assessment of the generality of these findings across regions and ecosystem types will only be possible once other long-term field experiments become available.

\section{Patchy forest regrowth after lag phase}

Pasture use was abandoned 15 years prior to our baseline census. However, for the first nine years, repeated accidental fires kept reverting tree woody biomass accumulation back to near $0 \mathrm{Mg} \cdot \mathrm{ha}^{-1} \cdot \mathrm{yr}^{-1}$, although fire intensity may have been spatially variable. During the first six years of postfire regrowth, total tree woody biomass accumulated slowly at a rate of $<1$ $\mathrm{Mg} \cdot \mathrm{ha}^{-1} \cdot \mathrm{yr}^{-1}$ (Davidson et al. 2004), which is comparable to other degraded sites after moderate to heavy pasture use in the region (Uhl et al. 1988). Similar postabandonment lag phases with negligible biomass accumulation elsewhere in Amazonia have been attributed to intensity and/or duration of prior land use (Feldpausch et al. 2007).

Between 6 and 12 years postfire, total woody biomass accumulation averaged $\sim 4 \mathrm{Mg} \cdot \mathrm{ha}^{-1} \cdot \mathrm{yr}^{-1}$, with high inter-plot variation, regardless of nutrient enrichment (Fig. 1b). This rate is at the far low end of the range reported for secondary forest biomass accumulation on non-sandy soils in Amazonia (Houghton et al. 2000, Zarin et al. 2001).

\section{Short-lived growth responses to nutrient addition}

The N-induced increase in tree biomass was due to both increased net tree recruitment into the $\geq 2 \mathrm{~cm} \mathrm{dbh}$ size class and to growth increments of larger trees of the two dominant species (Rollinia exsucca and Z. rhoifolium). Surprisingly, mean rates of total woody biomass accumulation (i.e., slopes in Fig. 1b) in control plots (no nutrients added) caught up with those in $+\mathrm{N}$ plots within five years following the last nutrient addition, despite the large amounts of $\mathrm{N}$ initially added. Davidson et al. (2004) reported that only $10 \%$ of the applied P and $20 \%$ of the applied $\mathrm{N}$ was incorporated into tree biomass during the first growing season after the first nutrient addition event. Apparently, this young secondary forest did not efficiently acquire and recycle enough of the added nutrients in bioavailable forms to maintain longer-term enhanced biomass accumulation relative to regrowth in the control plots.

Davidson et al. (2004) could not quantify the fate of most of the added $\mathrm{N}$ earlier during this experiment, because soil stocks of total $\mathrm{N}$ are large relative to the $\mathrm{N}$ amendments. Rapid immobilization of added nutrients in the soil was inferred from the strong net immobilization capacity and a highly conservative $\mathrm{N}$ cycle in these plots (Davidson et al. 2004) and in other secondary forests in the region (Verchot et al. 1999, Davidson et al. 2007). Immobilization of nutrients into soil pools unavailable to tree roots may be responsible for the short duration of the nutrient response. For instance, Nepstad et al. (1996) observed responses to added nutrients in planted trees at the same site only after soil tilling, which indicates that this compacted clay soil limits access by tree roots to added nutrients. Thus, in the present study, it appears that most of the added $\mathrm{N}$ had become immobilized into nonavailable pools of organic matter within a few years of addition, so that the initial nutrient response was not sustained.

These earlier studies at the same site support the notion that biomass accumulation reverted to be limited by $\mathrm{N}$ within a few years of our two pulse nutrient additions. Indeed, chronosequence studies suggest that $\mathrm{N}$ limitation in young secondary forests slowly declines relative to $\mathrm{P}$ limitation over several decades, as forests accumulate actively cycling N (Davidson et al. 2007). However, tree biomass accumulation of individual species may also be co-limited by other factors (Tanner et al. 1998). This was supported by increases in leaf $P$ concentrations of $Z$. rhoifolium and leaf $\mathrm{N}$ of both dominant tree species induced by nutrient addition earlier in the present experiment (Davidson et al. 2004) and in other tree species (Gehring et al. 1999).

\section{Shifts in tree species biomass}

Responses of tree species to added nutrients contrast with findings by Gehring et al. (1999), $200 \mathrm{~km}$ north of 

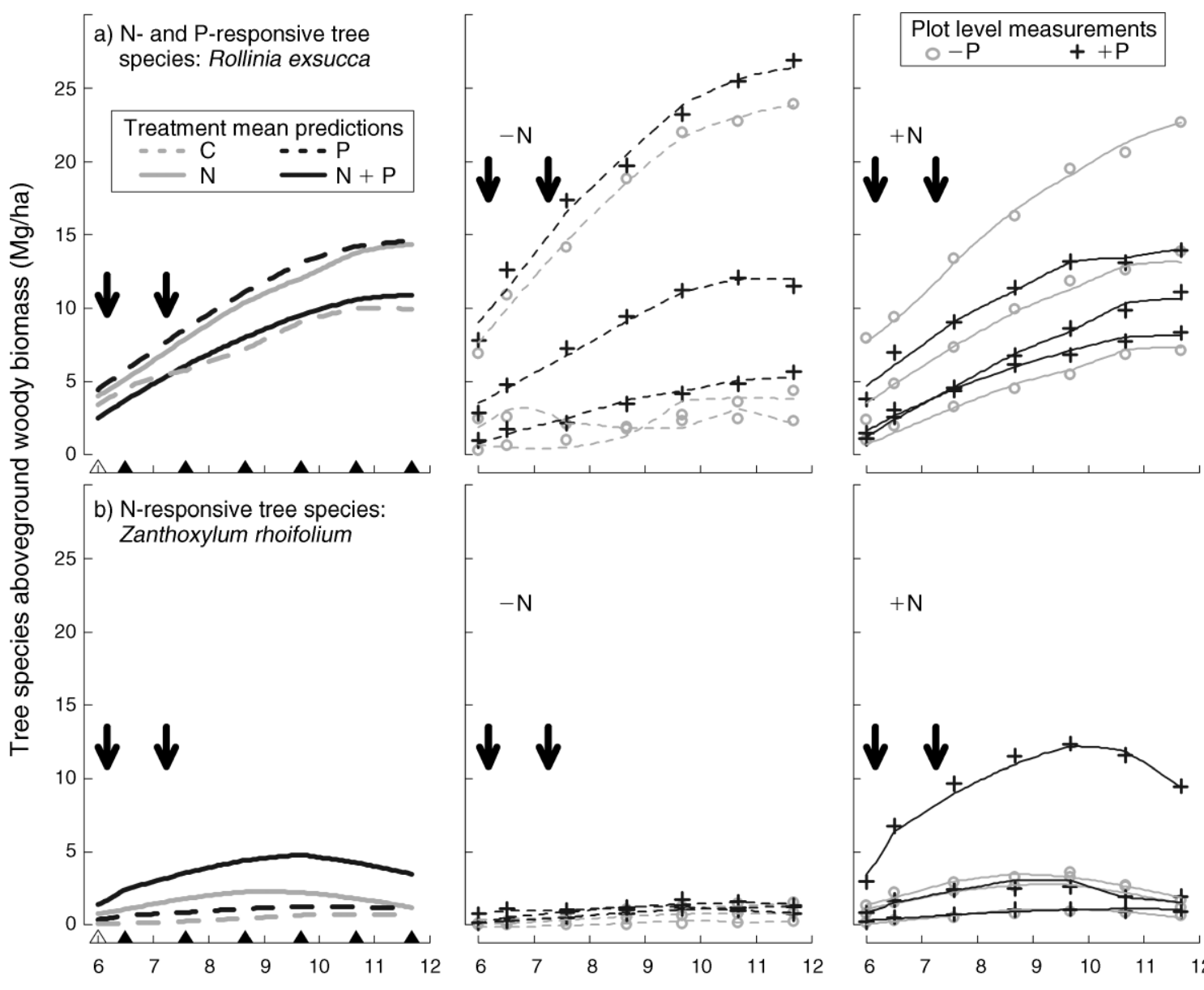

Time of regrowth (years since last fire)

FIG. 3. Trajectories of species woody biomass in secondary regrowth in response to factorial $\mathrm{N}$ and $\mathrm{P}$ addition in abandoned pasture, Brazilian Amazonia. Second-order polynomial mixed-model predictions (covariate: density of individuals, linearly interpolated between censuses). Left-hand panels show predictions (i.e., best linear unbiased predictors, BLUP) for treatment means (fixed effects of mixed models). Triangles on the $x$-axis indicate timing of censuses. Middle panels (controls and $\mathrm{P}$ only) and right-hand panels $(\mathrm{N}$ only and $\mathrm{N}+\mathrm{P}$ ) show all plot-level measurements and plot-level predictions. Arrows indicate timing of nutrient additions. For all fitted equations, see Appendix C. (a) Aboveground woody biomass of a single tree species with significant $\mathrm{N}$-only and $\mathrm{P}$-only responses. (b, c) Aboveground woody biomass of two tree species with significant $\mathrm{N}$-only responses. (d) Pooled aboveground woody biomass of all 55 remaining tree species (no significant nutrient response).

our site. For instance, at their sandy site $R$. exsucca did not respond to $\mathrm{N}$ or $\mathrm{P}$ addition, but $V$. guianensis was primarily $\mathrm{N}$-limited, and $B$. guianensis responded vigorously not only to $\mathrm{N}$, but also $\mathrm{P}$. These differences relate to species that all occurred at sufficiently high abundances at our site to allow detection of treatment effects. Possible explanations for the contrasting results may relate to immediate nutrient addition after fire, high sand content (Zarin et al. 2001), and/or arable cropping history (Moran et al. 2000) at the site studied by Gehring et al. (1999). Given such variation among sites, the results cannot be generalized at the species' response level. By contrast, at the community level, we speculate that further research could demonstrate that nutrient enrichment may commonly delay species accrual in secondary forests, as observed in the present study.

\section{Negative effects on tree species diversity}

Consistent negative effects of nutrient addition on all tree species diversity measures examined provide strong evidence that both $\mathrm{N}$-only and $\mathrm{P}$-only addition delayed increases in tree species richness and reduced evenness. The duration of these effects coincided with the positive biomass responses of three common tree species. This suggests that in tropical secondary forests, enrichment with a (co-)limiting nutrient may increase dominance of species that are capable of monopolizing other resources limiting to coexisting tree species. To our knowledge, such effects have so far only been demonstrated in relatively simple ecosystems and have been predicted from theory and from simulations (Fahey et al. 1998, Wilson and Tilman 2002, Herbert et al. 2004). 


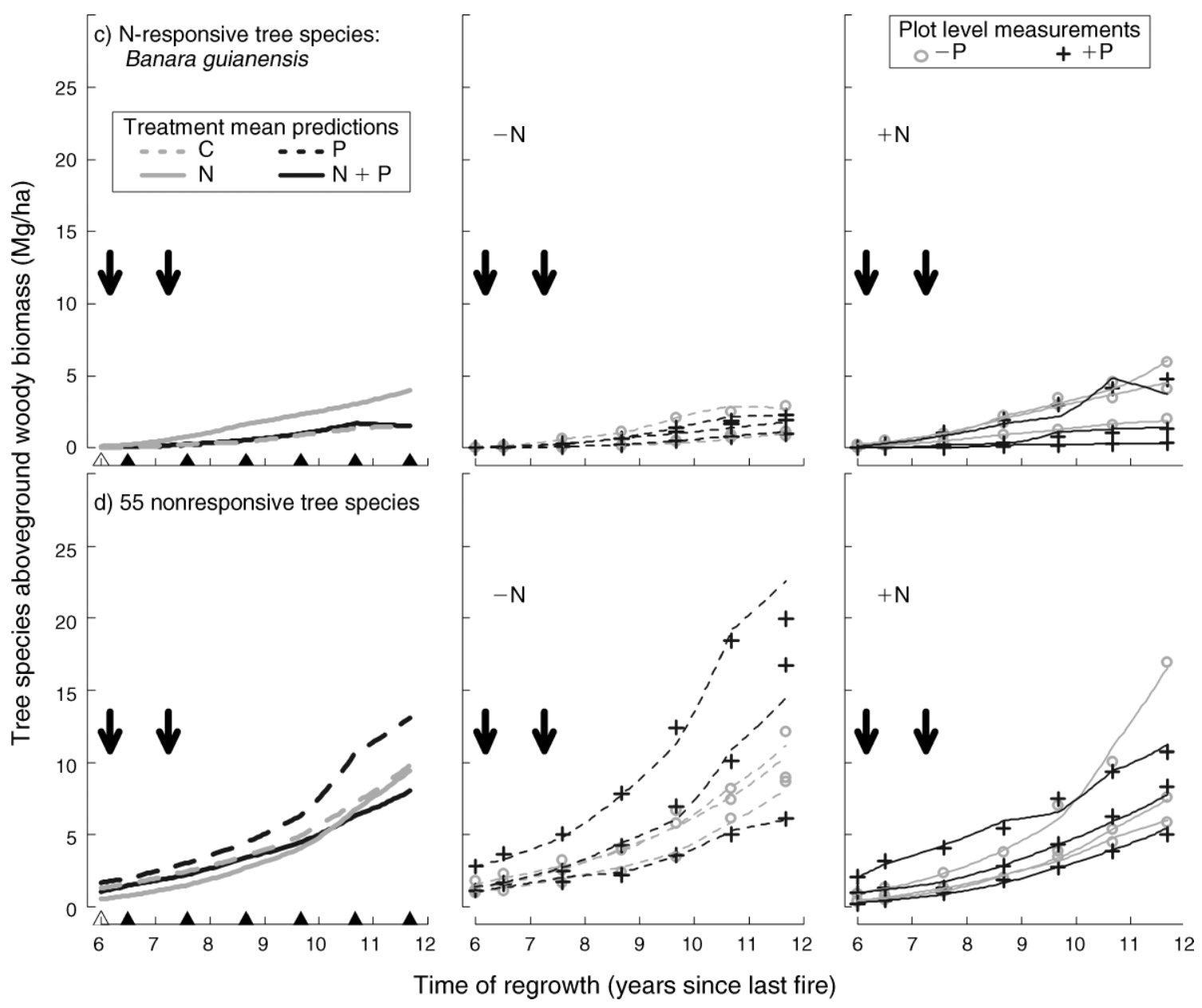

FIG. 3. Continued.

Nitrogen limitation of primary productivity is an important predictor of plant species loss following $\mathrm{N}$ enrichment, partly due to intensified competitive exclusion (Clark et al. 2007). By contrast, P enrichment did not significantly stimulate biomass growth of the pooled tree assemblage, yet had a disproportionately large negative impact on tree species diversity. This demonstrates that $\mathrm{P}$ enrichment might reduce species diversity without measurably increasing overall productivity, possibly by directly inhibiting some of the diverse range of species adapted to mobilizing $\mathrm{P}$ from unavailable pools in soils with low $\mathrm{P}$ availability (Lambers et al. 2008).

However, we found no obvious functional grouping among responsive species, as successional characteristics, leaf nutrient concentrations, and specific leaf areas varied within responsive species, as well as within nonresponsive species (data not shown). Further research is needed to identify ecophysiological characteristics and functional traits differentiating species favored from species disadvantaged by nutrient enrichment and underlying competitive mechanisms responsible for tropical species loss. Such understanding may help predict and ultimately prevent prolonged persistence of pioneers delaying colonization by mature forest species (Mesquita et al. 2001, Martínez-Garza and Howe 2003).

\section{Negative $N \times P$ interactions}

Surprisingly in this context, $\mathrm{N}+\mathrm{P}$ addition had a consistently weaker effect than $\mathrm{N}$ only and $\mathrm{P}$ only, both on tree species biomass and diversity measures. In contrast, a strong positive $\mathrm{N} \times \mathrm{P}$ interaction in enhancing biomass accumulation has been widely demonstrated in aquatic and terrestrial ecosystems (Elser et al. 2007).

The timing of our observed negative $\mathrm{N} \times \mathrm{P}$ interaction in tree species biomass and diversity responses coincided with a dramatic initial $\mathrm{N}+\mathrm{P}$ response by remnant grass biomass, as well as grass leaf $\mathrm{P}$ concentrations (Davidson et al. 2004). Simultaneous to $\mathrm{N}$ and $\mathrm{P}$ effects on tree biomass, grass biomass responses were also reversed within five years and were not significant for P-only or N-only additions (Fig. 1c). Herbs, shrubs, and vines have previously been reported to effectively compete with tropical secondary forest trees for added nutrients, 
especially $\mathrm{P}$, potentially retarding tree biomass accumulation (Harcombe 1977, Gehring et al. 1999). In contrast to other studies, our $\mathrm{N}+\mathrm{P}$ addition markedly increased the grass:tree biomass ratio for several years, even though trees had already successfully competed with grasses for the previous six years postfire. We did not determine herbaceous species composition and thus cannot rule out a positive $\mathrm{N} \times \mathrm{P}$ interaction in grass and/or forb species loss, as has been demonstrated in grasslands (Fynn and O'Connor 2005, Harpole and Tilman 2007). However, our data highlight that synergistic effects of combined $\mathrm{N}+\mathrm{P}$ enrichment on grass biomass responses may prevent synergistic $\mathrm{N}+\mathrm{P}$ responses in tree biomass and tree species diversity. Such interactions could have important implications for ecological dynamics and biodiversity, both in regenerating forests, as well as in savannas after nutrient enrichment, for instance by intensive agriculture.

\section{ACKNOWLEDGMENTS}

We thank Moacyr Dias-Filho, Marysol Schuler, and Carlos Alberto Silva for assistance with the experimental work and plant ID, and Instituto de Pesquisa Ambiental da Amazônia and Museu Paraense Emílio Goeldi for logistical support. We also thank L. M. Ryan, M. M. C. Bustamante, and two anonymous reviewers for critical comments and helpful suggestions. This research was supported by grants numbers NCC5-332, NCC5686, and NNG06GE88A of NASA's Terrestrial Ecology Program and is part of the Largescale Biosphere-Atmosphere project (LBA-ECO). I. Siddique was supported by the NASA Planetary Biology Internship, the University of Queensland, and the Woods Hole Research Center.

\section{Literature Cited}

Benner, J. W., and P. M. Vitousek. 2007. Development of a diverse epiphyte community in response to phosphorus fertilization. Ecology Letters 10:628-636.

Bobbink, R., M. Hornung, and J. G. M. Roelofs. 1998. The effects of air-borne nitrogen pollutants on species diversity in natural and semi-natural European vegetation. Journal of Ecology 86:717-738.

Bobbink, R., et al. 2010. Global assessment of nitrogen deposition effects on terrestrial plant diversity: a synthesis. Ecological Applications 20:30-59.

Chazdon, R. L. 2003. Tropical forest recovery: legacies of human impact and natural disturbances. Perspectives in Plant Ecology, Evolution and Systematics 6:51-71.

Chazdon, R. L. 2008. Chance and determinism in tropical forest succession. Pages 384-408 in W. Carson and S. Schnitzer, editors. Tropical forest community ecology. Blackwell, Malden, Massachusetts, USA.

Clark, C. M., E. E. Cleland, S. L. Collins, J. E. Fargione, L. Gough, K. L. Gross, S. C. Pennings, K. N. Suding, and J. B. Grace. 2007. Environmental and plant community determinants of species loss following nitrogen enrichment. Ecology Letters 10:596-607.

Davidson, E. A., C. J. R. Carvalho, A. M. Figueira, F. Y. Ishida, J. Ometto, G. B. Nardoto, R. T. Sabá, S. N. Hayashi, E. C. Leal, I. C. G. Vieira, and L. A. Martinelli. 2007. Recuperation of $\mathrm{N}$ cycling in Amazonian forests following agricultural abandonment. Nature 447:995-998.

Davidson, E. A., C. J. R. de Carvalho, I. C. G. Vieira, R. d. O. Figueiredo, P. Moutinho, F. Y. Ishida, M. T. P. dos Santos, J. B. Guerrero, K. Kalif, and R. T. Sabá. 2004. N and P limitation of biomass growth in a tropical secondary forest. Ecological Applications 14:S150-S163.
Dias-Filho, M. B., E. A. Davidson, and C. J. R. Carvalho. 2001. Linking biogeochemical cycles to cattle pasture management and sustainability in the Amazon Basin. Pages 84-105 in M. E. McClain, R. L. Victoria, and J. E. Richey, editors. The biogeochemistry of the Amazon Basin. Oxford University Press, New York, New York, USA.

Ellsworth, D. S., and P. B. Reich. 1996. Photosynthesis and leaf nitrogen in five Amazonian tree species during early secondary succession. Ecology 77:581-594.

Elser, J. J., M. E. Bracken, E. Cleland, D. S. Gruner, W. S. Harpole, H. Hillebrand, J. Ngai, E. W. Seabloom, J. Shurin, and J. E. Smith. 2007. Global analysis of $\mathrm{N}$ and P limitation of primary producers in freshwater, marine and terrestrial ecosystems. Ecology Letters 10:1135-1142.

Fahey, T. J., J. J. Battles, and G. F. Wilson. 1998. Responses of early successional northern hardwood forests to changes in nutrient availability. Ecological Monographs 68:183-212.

Falkowski, P., et al. 2000. The global carbon cycle: a test of our knowledge of earth as a system. Science 290:291-296.

Feldpausch, T. R., C. D. Prates-Clark, E. C. M. Fernandes, and S. J. Riha. 2007. Secondary forest growth deviation from chronosequence predictions in central Amazonia. Global Change Biology 13:967-979.

Fynn, R. W. S., and T. G. O'Connor. 2005. Determinants of community organization of a South African mesic grassland. Journal of Vegetation Science 16:93-102.

Gehring, C., M. Denich, M. Kanashiro, and P. L. G. Vlek. 1999. Response of secondary vegetation in Eastern Amazonia to relaxed nutrient availability constraints. Biogeochemistry 45:223-241.

Gilliam, F. S. 2006. Response of the herbaceous layer of forest ecosystems to excess nitrogen deposition. Journal of Ecology 94:1176-1191.

Harcombe, P. A. 1977. Influence of fertilization on some aspects of succession in a humid tropical forest. Ecology 58: $1375-1383$.

Harpole, W. S., and D. Tilman. 2007. Grassland species loss resulting from reduced niche dimension. Nature 446:791-793.

Herbert, D. A., E. B. Rastetter, L. Gough, and G. R. Shaver. 2004. Species diversity across nutrient gradients: an analysis of resource competition in model ecosystems. Ecosystems 7: 296-310.

Houghton, R. A., D. L. Skole, C. A. Nobre, J. L. Hackler, K. T. Lawrence, and W. H. Chomentowski. 2000. Annual fluxes of carbon from deforestation and regrowth in the Brazilian Amazon. Nature 403:301-304.

Howarth, R. W., K. Ramakrishna, E. Choi, R. Elmgren, L. A. Martinelli, A. Mendoza, W. Moomaw, C. Palm, R. Roy, M. Scholes, and Z. Zhao-Liang. 2005. Nutrient management. Pages 295-311 in Ecosystems and human well-being. Volume 3. Policy Responses. Island Press, Washington, D.C., USA. 〈http://www.millenniumassessment.org/en/Responses.aspx $\rangle$

Jipp, P. H., D. C. Nepstad, D. K. Cassel, and C. R. de Carvalho. 1998. Deep soil moisture storage and transpiration in forests and pastures of seasonally-dry Amazonia. Climatic Change 39:395-412.

Kauffman, J. B., D. L. Cummings, D. E. Ward, and R. Babbitt. 1995. Fire in the Brazilian Amazon: 1. Biomass, nutrient pools, and losses in slashed primary forests. Oecologia 104: 397-408.

Lambers, H., J. A. Raven, G. R. Shaver, and S. E. Smith. 2008. Plant nutrient-acquisition strategies change with soil age. Trends in Ecology and Evolution 23:95-103.

Lawrence, D. 2003. The response of tropical tree seedlings to nutrient supply: meta-analysis for understanding a changing tropical landscape. Journal of Tropical Ecology 19:239-250.

Markewitz, D., E. Davidson, P. Moutinho, and D. Nepstad. 2004. Nutrient loss and redistribution after forest clearing on a highly weathered soil in Amazonia. Ecological Applications 14(Supplement):S177-S199. 
Martínez-Garza, C., and H. F. Howe. 2003. Restoring tropical diversity: beating the time tax on species loss. Journal of Applied Ecology 40:423-429.

Mesquita, R. C. G., K. Ickes, G. Ganade, and G. B. Williamson. 2001. Alternative successional pathways in the Amazon Basin. Journal of Ecology 89:528-537.

Moran, E. F., E. S. Brondizio, J. M. Tucker, M. C. da SilvaForsberg, S. McCracken, and I. Falesi. 2000. Effects of soil fertility and land-use on forest succession in Amazonia. Forest Ecology and Management 139:93-108.

Nepstad, D. C., C. R. de Carvalho, E. A. Davidson, P. H. Jipp, P. A. Lefebvre, G. H. Negreiros, E. D. da Silva, T. A. Stone, S. E. Trumbore, and S. Vieira. 1994. The role of deep roots in the hydrological and carbon cycles of Amazonian forests and pastures. Nature 372:666-669.

Nepstad, D. C., C. Uhl, C. A. Pereira, and J. M. C. da Silva. 1996. A comparative study of tree establishment in abandoned pasture and mature forest of eastern Amazonia. Oikos 76:25-39.

Oksanen, J., R. Kindt, P. Legendre, B. O’Hara, M. Henry, and H. Stevens. 2007. Vegan: community ecology package. R package version 1.8-8. 〈http://r-forge.r-project.org/projects/ vegan/>

Ostertag, R., and J. H. Verville. 2002. Fertilization with nitrogen and phosphorus increases abundance of non-native species in Hawaiian montane forests. Plant Ecology 162:7790.

Pinheiro, J., D. Bates, S. DebRoy, and D. Sarkar, R Development Core Team. 2007. nlme: linear and nonlinear mixed effects models. R package version 3.1-83. 〈http://cran. r-project.org/doc/packages/nlme.pdf $\rangle$

R Development Core Team. 2007. R: a language and environment for statistical computing. Version 2.5.0. R Foundation for Statistical Computing, Vienna, Austria.
Sombroek, W. G. 1966. Amazon soils, a reconnaissance of the soils of the Brazilian Amazon region. Center for Agricultural Publications and Documents, Wageningen, The Netherlands.

Tanner, E. V. J., P. M. Vitousek, and E. Cuevas. 1998. Experimental investigation of nutrient limitation of forest growth on wet tropical mountains. Ecology 79:10-22.

Uhl, C., R. Buschbacher, and E. A. S. Serrão. 1988. Abandoned pastures in Eastern Amazonia: 1. Patterns of plant succession. Journal of Ecology 76:663-681.

Verchot, L. V., E. A. Davidson, J. H. Cattanio, I. L. Ackerman, H. E. Erickson, and M. Keller. 1999. Land use change and biogeochemical controls of nitrogen oxide emissions from soils in eastern Amazonia. Global Biogeochemical Cycles 13: $31-46$.

Vieira, I. C. G., C. Uhl, and D. Nepstad. 1994. The role of the shrub Cordia multispicata Cham. as a 'succession facilitator' in an abandoned pasture, Paragominas, Amazônia. Vegetatio 115:91-99.

Vitousek, P. M., and R. L. Sanford. 1986. Nutrient cycling in moist tropical forest. Annual Review of Ecology and Systematics 17:137-167.

Wassen, M. J., H. O. Venterink, E. D. Lapshina, and F. Tanneberger. 2005. Endangered plants persist under phosphorus limitation. Nature 437:547-550.

Williams, M. R., and J. M. Melack. 1997. Solute export from forested and partially deforested catchments in the central Amazon. Biogeochemistry 38:67-102.

Wilson, S. D., and D. Tilman. 2002. Quadratic variation in oldfield species richness along gradients of disturbance and nitrogen. Ecology 83:492-504.

Zarin, D. J., M. J. Ducey, J. M. Tucker, and W. A. Salas. 2001. Potential biomass accumulation in Amazonian regrowth forests. Ecosystems 4:658-668.

\section{APPENDIX A}

Univariate statistical procedure and detailed responses of vegetation structure (Ecological Archives E091-147-A1).

\section{APPENDIX B}

Quantification and detailed responses of tree species diversity (Ecological Archives E091-147-A2).

\section{APPENDIX C}

Detailed responses of absolute tree species woody biomass (Ecological Archives E091-147-A3). 